\title{
Experiências Organizacionais de Resistência ao Processo de Empresariamento Urbano: O Caso da Comunidade Vila Autódromo
}

\author{
Organizational Experiences of Resistance to the Urban Entrepreneurship Process: The \\ Case of the Vila Autódromo Community
}

\author{
Gabriela Izabel de Alvarenga ${ }^{1}$ \\ Leonardo Vasconcelos Cavalier Darbilly ${ }^{2}$
}

\begin{abstract}
Resumo
Com a aproximação dos Jogos Olímpicos de 2016, acirrou-se no Rio de Janeiro o processo de "empresariamento urbano" (HARVEY, 1996), tendo como uma das consequências o aumento do número absoluto de remoções urbanas (BETIM, 2015). A Vila Autódromo foi uma das comunidades ameaçadas de remoção, porém com ações de oposição a esse processo criaram-se obstáculos significativos aos objetivos traçados pelo poder público, no que diz respeito a essa política, dando notoriedade a tal comunidade. Assim, objetiva-se analisar como movimentos de resistência, por parte de diferentes atores sociais, podem ocorrer em contraposição a fenômenos como o do empresariamento urbano, tendo como pano de fundo o caso da Vila Autódromo. Para alcançar este objetivo, realizou-se um estudo qualitativo por meio da coleta de entrevistas individuais, observações participantes e pesquisa documental. Assim, os dados apontaram que a luta envolveu ações de resistência dos próprios moradores e de outros diferentes aliados, a partir de uma organização plural na comunidade. A Vila Autódromo demonstrou ser o que Parker, Fournier e Reedy (2012) classificam como uma experiência de um modo alternativo de organizar a sociedade, algo para além das leis econômicas inexoráveis que dominam a maior parte do planeta. Assim, concluiu-se, portanto, que as ações de oposição foram parte do organizar construído na Vila Autódromo e a materialização da resistência na comunidade.
\end{abstract}

Palavras-chave: Organizações Alternativas. Resistência. Vila Autódromo.

\begin{abstract}
With the approach of the 2016 Olympic Games, the "urban entrepreneurship" process was intensified in Rio de Janeiro (HARVEY, 1996), one of the consequences being the increase in the absolute number of urban removals (BETIM, 2015). Vila Autódromo was one of the communities threatened with it, however with actions in opposition to this process, significant obstacles were created to the objectives set by the public authorities concerning this policy, giving the community notoriety. Thus, we objective to analyze how resistance movements, by different social actors, can occur in opposition to phenomena such as urban entrepreneurship, against the background of the case of Vila Autódromo. A qualitative study was carried out to achieve this objective through individual interviews collection, participant observations, and documentary research. Thus, the data showed that the struggle involved resistance actions by the residents themselves and other different allies, based on a plural organization in the community. Vila Autódromo proved to be what Parker, Fournier, and Reedy (2012) classify as an experience of an alternative way of organizing society, something beyond the inexorable economic laws that dominate most of the planet. Thus, it was concluded, therefore, that the opposition actions were part of the organizing built in Vila Autódromo and the materialization of resistance in the community.
\end{abstract}

Keywords: Alternative Organizations. Resistance. Vila Autódromo.

Mestra em Administração pela Universidade Federal Rural do Rio de Janeiro (UFRRJ). Possui pós-graduação lato-sensu em Gestão Pública Municipal pela Universidade Federal Fluminense (UFF).

Doutor em Administração e Mestre em Administração Pública pela Escola Brasileira de Administração Pública e de Empresas da Fundação Getulio Vargas (EBAPE/FGV). Professor adjunto do Departamento de Administração e Turismo do Instituto Multidisciplinar da Universidade Federal Rural do Rio de Janeiro (UFRRJ). 


\section{INTRODUÇÃO}

As ações implementadas por formas não convencionais de organização contribuem para o rompimento de paradigmas hegemônicos e têm sido objeto de trabalhos na área de estudos organizacionais críticos, tendo em vista que são capazes de possibilitar diferentes formas de a sociedade se organizar e manifestar suas demandas (MISOCZKY, 2010; COSTA, 2018).

O presente estudo envolve experiências organizacionais de resistência ao fenômeno conhecido por empresariamento urbano. O objetivo principal do empresariamento urbano é atrair empresas privadas por meio da criação de uma serie de precondições que tornem o investimento empresarial lucrativo, tendo o governo local passa a sustentar tais empresas, participando, então, de seus custos de produção (HARVEY, 1996). Além disso, os megaeventos acirram esse processo, pois ampliam as estratégias relacionadas à política mercadológica com o intuito de tornar a cidade palco de grandes investimentos públicos e privados.

A partir dos anos 1990, tornou-se prática hegemônica a utilização de megaeventos esportivos como forma de se lançar as cidades-sedes de forma midiática, associando a imagem da cidade à renovação de suas infraestruturas, por meio do protagonismo da indústria imobiliária e do setor de construção (ROLNIK, 2016), como, por exemplo, os Jogos Olímpicos em 2016, que impactaram a cidade do Rio de Janeiro em diversos âmbitos. Assim, com a justificativa de se cumprir um conjunto de intervenções urbanísticas preestabelecidas pelo Comitê Olímpico Internacional (COI) (MASCARENHAS, 2014), a prefeitura multiplicou as parcerias com as iniciativas privadas. Entretanto, atender a essas exigências envolve um alto dispêndio de recursos. Além disso, há uma tendência de a cidade-sede aproveitar o megaevento para apostar na construção de grandiosos projetos de paisagem urbana, a partir de uma coalizão entre o governo e o setor de construção civil, ambos possuidores de grandes interesses imobiliários (MASCARENHAS, 2014).

Neste sentido, a cidade olímpica não se torna apenas detentora de novas instalações e de ajustes nos sistema de mobilidade, mas passa a subordinar-se mais fortemente aos interesses do grande capital (MASCARENHAS, 2014).

Dentro deste contexto, a região da subprefeitura da Barra e Jacarepaguá, localizada na zona oeste da cidade do Rio de Janeiro, foi selecionada para receber instalações para os Jogos Olímpicos de 2016, recepcionando mais da metade dos eventos (TAFAKGI, 2014). Desde os anos 80, a zona oeste é o foco central da expansão urbana na cidade do Rio de Janeiro, havendo, a partir dessa década, especialmente na Barra e em Jacarepaguá, uma explosão demográfica na qual quase todos os terrenos passaram a ser ocupados por luxuosos condomínios residenciais, shoppings centers, prédios comerciais e etc.

O Parque Olímpico viria a ser o coração dos Jogos de 2016, principal palco das competições envolvendo o evento. Porém, a região selecionada para a construção do Parque Olímpico e para as demais infraestrutras no entorno não era desabitada. Ao contrário, existia uma comunidade que abrigava mais de mil moradores, alguns deles com Concessão de Direito Real de Uso, instrumento de Política Urbana utilizado em processos de regularização fundiária que dá o direito de uso de terras públicas para moradia popular (MONTEIRO; MEDEIROS, 2016). Além disso, essa comunidade, denominada Vila Autódromo, estava resguardada como Área de Especial Interesse Social (AEIS), que são áreas destinadas à implantação de programas e empreendimentos de interesse social, vinculados ao uso habitacional. Fora essas documentações legais, desde 1987, a Vila Autódromo estava organizada por meio da Associação de Moradores Pescadores e Amigos da Vila Autódromo (AMPAVA). A Associação era regularmente constituída, detentora de estatuto, sede própria e de ampla representatividade.

Mesmo com essas garantias legais, os moradores da Vila Autódromo recebiam ameaças de remoção desde 1992: inicialmente, por argumentos envolvendo questões estéticas; depois, para abrigar instalações para os Jogos Pan-Americanos; em seguida, para as alças viárias do sistema de Bus Rapid Transit ou Transporte Rápido por Ônibus (BRT), que é um sistema de transporte coletivo; e para a construção do estacionamento e do Centro de Mídia e implantação dos acessos ao Parque Olímpico (MONTEIRO; MEDEIROS, 2016).

Entretanto, na medida em que se aumentava a possibilidade de remoção, maior tornou-se a contestação a esse processo. Diferentes grupos questionavam a necessidade, a legalidade e os interesses envolvidos, ampliando-se a luta contra as remoções na comunidade. Assim, essa luta veio a envolver os próprios moradores e diferentes aliados, como pesquisadores de universidades, movimentos sociais, integrantes da Defensoria Pública do Estado do Rio de Janeiro, representantes da Igreja Católica, mídias alternativas, entre outros, que se organizaram para realizar ações de resistência. Essa luta e consequentemente essa união nos ensinam, empiricamente, que o organizar vai muito além do que ocorre em empresas verticais orientadas pelas políticas neoliberais que buscam alcançar, de forma eficiente, objetivos e metas racionalmente preestabelecidos.

A partir desse contexto, portanto, este artigo possui como principal objetivo analisar como experiências organizacionais alternativas podem atuar em contraposição a fenômenos tais como o do empresariamento urbano, tendo como pano de fundo o caso da Vila Autódromo. Sendo assim, tal comunidade é aqui analisada como uma organização de resistência formada por diferentes grupos de atores que implementam distintas ações com objetivos semelhantes, qual sejam, deter o processo de remoção perpetrado pelo poder público.

Do ponto de vista teórico e metodológico, a proposta deste estudo é contribuir para o enriquecimento dos estudos críticos no contexto social brasileiro e a partir do espaço disciplinar da Administração. Diante do cenário de colapso 
econômico, social e ambiental, torna-se necessário voltar o olhar para experiências organizacionais que resistem ao sistema social e econômico dominante (COSTA, 2018). Não é mais possível ignorar a importância de toda gama de grupos da sociedade civil que estão ativamente envolvidos em lutas contra os discursos do management. Tais grupos são atores sociais que questionam a prevalência desses discursos no setor público: moradores que discutem sobre a dominação do espaço público por uma lógica empresarial; mulheres que questionam o viés masculino nesses discursos; e manifestantes angustiados pela imposição do management por organismos multinacionais (SPICER, BÖHM, 2007).

Assim, a partir desse exemplo de organização de resistência que surgiu no âmbito da Vila Autódromo, esperase contribuir para a ampliação dos estudos críticos no contexto brasileiro, promovendo a reflexão e a colaboração para formas alternativas de se pensar as organizações.

\section{REFERENCIAL TEÓRICO}

\subsection{Remoções e organizações de resistência}

De acordo com Cernea (1993) nem sempre as justificativas usadas para que as remoções aconteçam são transparentes, ou seja, muitos programas de remoção acabam sendo justificados pela necessidade de implementação de alguma política social, apresentadas apenas como abordagens veladas para fornecer bens imobiliários valiosos para usuários de alto poder aquisitivo (CERNEA, 1993). Ainda de acordo com o autor, há uma grande quantidade de remoções, ocorridas especialmente em favelas, justificadas por razões estéticas ou para acomodação de grandes eventos e programas não-urbanos, sem ser resultado de projetos urbanos em si (CERNEA, 1993). Assim, tal justificativa - seja ela envolvendo crescimento econômico urbano ou melhoria ambiental, ou necessidade de acomodar grandes eventos, como jogos internacionais, feiras, conferências, etc. - não torna, necessariamente, a remoção menos dolorosa para a população residente (CERNEA, 1993).

Assim, de maneira geral, as remoções envolvem diferentes setores e organizações, sendo uma questão de direitos humanos (ONU, 2010) ${ }^{1}$. Seus efeitos são profundos, pois podem desfazer grupos de parentesco e de cadeias informais de solidariedade comunitária (CERNEA, 1994). Além disso, apesar de ilegais, existem casos de remoção acompanhados de brutalidade e violência, ou que resultaram em indivíduos e famílias desabrigados e/ou sem acesso a meios de sobrevivência (ONU, 2010).

Segundo Cernea (1993), quando se intensifica a concorrência por áreas urbanas para atender ao crescimento econômico urbano, os setores público e privado se interessam em forçar a saída dos moradores locais para que essas áreas sirvam a interesses comerciais, bancários ou industriais - sendo, em alguns casos, construídas residências para populações de renda alta - substituindo comunidades/favelas (CERNEA, 1993). Em circunstâncias como essas, é possível inferir que as remoções estejam relacionadas à adoção de uma política de "empresariamento urbano" (HARVEY, 1996), cujo objetivo é o investimento e desenvolvimento econômico por meio de empreendimentos imobiliários pontuais e especulativos em detrimento da melhoria das condições do território (HARVEY, 1996). Assim, é possível dizer que essa política seja sustentada ideologicamente pelos discursos do management, que preza por um organizar contido nas empresas, mas que tem sido aplicado em diferentes setores, modificando linguagens e conceitos (PARKER, 2002; SOLÉ, 200; BÖHM, 2006), naturalizando valores e práticas do mundo dos negócios. Alunos e usuários do serviço público se tornaram clientes, atletas em mercadoria (SOLÉ, 2003), trabalhadores são colaboradores. Enfim, é como se a influência dos negócios em nosso mundo tornasse impossível imaginar outra forma de organização.

Porém, apesar da aparente unicidade do discurso do management, há abertura à contestação e resistência (SPICER; BÖHM, 2007). A partir disso, surgem experiências de pensamento sobre modos alternativos de organizar a sociedade (PARKER; FOURNIER; REEDY, 2012). São organizações que ultrapassam o significado de "organização" preestabelecido, de algo formalmente constituído, restrito a entidades e instituições formais (BOHM, 2006) e com práticas organizacionais verticais, pautadas pela eficiência, pela concentração de poder, por regras legitimadas e pelo controle (MISOCZKY; MORAES, 2011). Pactua-se com a concepção de que há um modo de organizar com práticas organizacionais horizontais, pautadas na participação direta dos moradores e com decisões tomadas coletivamente.

Lightfoot (2013) enfatiza a importância de se pensar as organizações como um processo aberto, para tanto, é preciso definir organização como um verbo e não como substantivo que demandaria pensá-la como uma entidade fixa. Lightfood (2013) e Parker et al. (2014) sugerem três orientações, valores, lógicas ou princípios para se pensar nas denominadas organizações alternativas. São eles: autonomia, solidariedade e responsabilidade com o futuro (LIGHTFOOD, 2013; PARKER et al., 2014). Qualquer alternativa precisa proteger a autonomia individual, a partir da ideia que os indivíduos devem ter escolhas, pois, caso não exista autonomia dentro de um sistema social, ou seja, caso existam apenas regras, prevalecerá o totalitarismo, a uniformidade e a intolerância à diferença (LIGHTFOOD, 2013; PARKER et al., 2014). Com o segundo princípio - o da solidariedade - compreende-se que sozinhos os seres humanos são vulneráveis e impotentes; coletivamente se tornam poderosos e capazes de transformar o mundo em seus propósitos (LIGHTFOOD, 2013; PARKER et al., 2014). No caso da resistência, é possível pensar em "solidariedade

1 Organização das Nações Unidas. 
antagônicas", ou seja, são perseguidos interesses coletivos contra coletividades concorrentes, na resistência contra inimigos (HOFFE, 2003). A solidariedade envolve, então, a noção de pertencimento a uma mesma comunidade, que pode representar "uma rede de relações próximas entre um número limitado de pessoas normalmente baseadas na interação face a face em uma área geográfica específica" (PARKER, FOURNIER, REEDY, 2012, p. 70). Já com o terceiro princípio - o da responsabilidade com o futuro - (LIGHTFOOD, 2013; PARKER et al., 2014), a questão é a impossibilidade de se postergar a busca de soluções para problemas de um futuro que nunca será diferente do presente caso a transformação não comece a ser construída a partir de agora (RAUBER, 2004). Assim, em relação às organizações de resistências às remoções, o relacionamento da população-alvo com o meio ambiente, e, particularmente, com a terra, a fertilidade, a disponibilidade de recursos e a relação entre o grupo, são laços que estão no cerne das construções individuais e coletivas contra as ameaças de remoção (OLIVER-SMITH, 1991).

Reflexões acerca do conceito de organização contribuem para o reconhecimento da pluralidade de formas e práticas organizacionais, que rompem com categorizações e tornam-se organizações sinônimos de empresas (COSTA, 2018). O que se constata, então, é a possibilidade de atuação das organizações alternativas por meio de ações de resistências que vão de encontro à visão de mundo do mercado, buscando outra forma de se pensar as organizações além da ótica empresarial. A resistência, de acordo com Hollander e Einwohner (2004), tem sido apresentada de diferentes maneiras na Academia. De acordo com os autores, quatro elementos estão constantemente presentes nos estudos sobre resistência: ação, oposição, reconhecimento e intenção (HOLLANDER; EINWOHNER, 2004). A ação e a oposição são elementos presentes na maioria dos estudos analisados pelos autores, pois estes constataram que a resistência é um comportamento ativo, podendo ser verbal, cognitivo ou físico (ação), além de ir constantemente de encontro a algo (oposição) (HOLLANDER; EINWOHNER, 2004). A visibilidade é um pré-requisito necessário para o terceiro elemento, ou seja, para o reconhecimento da resistência; porém, a forma como os resistentes lidam com esse reconhecimento pode variar entre manipulação e comportamento, por necessidade de ocultar a ação (HOLLANDER; EINWOHNER, 2004). O reconhecimento depende dos objetivos dos resistentes, que podem tentar esconder o ato em si ou a intenção por trás dele (HOLLANDER; EINWOHNER, 2004). Identificar uma ação como resistência, portanto, depende dos alvos - a quem a ação é dirigida - e dos observadores - espectadores no momento da resistência, como a mídia, pesquisadores (HOLLANDER; EINWOHNER, 2004). De acordo com Parker, Fournier e Reedy (2012), a resistência pode se dar por meio de ações diretas, que incluem táticas - como greve de fome, piquetes, vigílias, ocupações, manifestações, bloqueios, boicotes e diversos atos de desobediência civil que não envolvam a política parlamentar -, podendo recorrer ao apoio indireto da mídia ou de instituições políticas. Outro meio de ação de resistência é a luta institucional, que, diferentemente das ações diretas, envolve o uso de canais, instâncias e recursos estatais, tais como conselhos gestores (SOUZA, 2012)

A mídia pode ser uma importante aliada, pois a informação é sempre um recurso crucial para um movimento de resistência, principalmente, em casos envolvendo direitos humanos (OLIVER-SMITH, 1991). Mais que ampliar o reconhecimento dessas ações, as mídias, se forem contra-hegemônicas, isto é, se opuserem ao status quo das mídias comerciais de grande porte, podem representar um canal de expressão de uma comunidade, em que os próprios resistentes manifestem suas necessidades, fomentando um processo educativo transformador (KAPLÚN, 1985; ATTON, 2002; KROHLING PERUZZO, 2008). A mídia, então, enquanto aliada, pode ampliar as ações de seu contexto local para o nível nacional e internacional, projetando o movimento no cenário mundial (OLIVER-SMITH, 1991). Outros aliados possíveis são: ONGS; associações de moradores; partidos políticos de oposição; grupos de estudantes; sindicatos; voluntários contrários a projetos de desenvolvimento que afetem os direitos humanos etc. (OLIVER-SMITH, 1991).

Para Laclau e Mouffe (1987), os movimentos sociais são os motores centrais, que se aproveitam continuamente da natureza frágil das formas tradicionais de organizações. Sendo assim, os movimentos sociais podem ser uma alternativa ao conceito hegemônico de organização dentro do campo disciplinar da Administração, pois são ações sociais coletivas que possibilitam formas diferentes de a população se organizar e expressar suas demandas (GOHN, 2011). Misoczky, Flores e Böhm (2008) sugerem a adoção da conduta prática teórica proposta por Böhm (2002), que se concretiza, por exemplo, no engajamento dos pesquisadores com os movimentos populares. Isso envolve a articulação entre o conhecimento elaborado em sua dimensão estritamente teórica e o conhecimento que emerge de baixo e que está contido nas práticas (RAUBER, 2004). Gohn (1991) ressalta a importância da troca de experiências nesses espaços que abrigam as práticas coletivas, para que as informações sejam socializadas, as identidades constituídas, os conhecimentos dos resultados obtidos por outros grupos absorvidos e as memórias de experiências passadas reavivadas (GOHN, 1991).

Assim, essa organização dos movimentos sociais passa a ser um "espaço para a aprendizagem" (MISOCZKY, 2010, p. 40) em que os participantes assimilam e realizam suas responsabilidades, visando ao consenso (MISOCZKY, 2010), por meio de uma ampla participação de todos os atores envolvidos.

\section{METODOLOGIA}

Para este estudo de natureza qualitativa, realizaram-se, inicialmente, observações participantes por meio 
da ida da pesquisadora a eventos dentro e fora da Vila Autódromo e na página do Facebook da comunidade de 2016 a 2018. A partir dessas observações, realizou-se a seleção das "sementes" que auxiliaram a seleção dos sujeitos entrevistados. Sementes são informantes-chaves capazes de auxiliar a pesquisadora a tatear quais seriam os entrevistados (VINUTO, 2014). Selecionaram-se quatro sementes: a Ex-Moradora 1 e ex-diretora social da Associação de Moradores; a Moradora 1; a Jornalista 1 e a Pesquisadora 1. Além das sementes, foram entrevistados dois vereadores, um deputado estadual, o assessor desse deputado estadual, uma representante da Pastoral de Favelas, dois padres, três ex-moradores - incluindo o ex-presidente da Associação de Moradores -, duas defensoras públicas e dois moradores. Assim, ao todo, foram realizadas 18 entrevistas individuais.

Além das entrevistas e da observação, realizou-se a análise dos seguintes documentos: último Plano Popular da Vila Autódromo e o Estatuto da Associação de Moradores e Pescadores da Vila Autódromo. Ao final desta fase de coleta, constatou-se a forte presença do Museu das Remoções como experiência organizacional de resistência ao fenômeno de empresariamento urbano. Sendo assim, posteriormente, os pesquisadores procederam a uma segunda fase de coleta de dados com foco nas redes sociais do próprio Museu das Remoções, privilegiando informações relativas especialmente ao período entre 2019 a 2020. Tal esforço teve como principal intuito verificar a situação mais recente tanto da comunidade de forma mais ampla, como dos diferentes grupos envolvidos com a luta que lá ocorreu.

Os dados coletados em ambas as fases de coleta foram analisados por meio da técnica de análise de conteúdo, a partir das seguintes categorias (em maiúsculo) e subcategorias (em minúsculo): REMOÇÕES URBANAS - empresariamento urbano; RESISTÊNCIA- ação e oposição; ORGANIZAÇÃO ALTERNATIVA- responsabilidade com o futuro, solidariedade e autonomia. A análise dos dados se deu da seguinte forma: primeiramente, foi feita a leitura de todos os dados coletados em conjunto e em seguida, a leitura individual. A partir disso, excluíram-se os pontos sem relevância para o alcance do objetivo estabelecido. Posteriormente, retomou-se às categorias e subcategorias construídas com base no referencial teórico adotado neste trabalho e estabeleceu-se o agrupamento dos dados relacionados a uma mesma categoria ou subcategoria. Por fim, foi feita a articulação entre os dados coletados e o conteúdo do referencial teórico, a partir de uma análise interpretativa. Já no que diz respeito à segunda fase de coleta de dados, ou seja, realizada com base nas redes sociais do Museu das Remoções, realizou-se uma leitura atenta das diferentes postagens realizadas no período acima supracitado, tendo todos os dados, que porventura pudessem ser relacionados às categorias de análise aqui privilegiadas, registrados de forma permanente, enquanto que informações não relevantes para a análise foram descartadas.

\section{RESULTADOS E DISCUSSÃO}

\subsection{Experiências organizacionais de resistência ao empresariamento urbano: o exemplo da comunidade Vila Autódromo}

A Vila Autódromo, antes das remoções, possuía um entorno quase sem edifícios e com uma paisagem natural bastante evidente. Segundo os dados coletados na entrevista, havia casas próximas a beira da lagoa (sendo uma pequena parcela possuidora de uma melhor condição financeira) e outras próximas à avenida. Porém, mesmo assim, a maioria dos moradores e ex-moradores afirmou ter vindo de outra região favelizada da cidade.

Uma característica da comunidade, constantemente presente nas falas dos entrevistados e no Plano Popular, era a ausência do poder público, como pode ser observado nos trechos a seguir. De acordo com o Deputado Estadual: "[havia] carências em relação aos serviços de atendimento de necessidades básicas da população". Já segundo a Moradora 2, não havia saneamento básico e existiam ruas com esgoto a céu aberto. A fala da Defensora Pública 1 vai ao encontro dessas afirmações quando menciona que "[...] o município não fez a parte que cabia ao município, então, toda a parte de urbanização, de calçamento, toda a parte que cabia ao município, ele não fez [...]".

Apesar disso, a Vila Autódromo era uma comunidade sem indícios explícitos da presença do tráfico de drogas ou de milícias. Corroboram a perspectiva de que era um local em que se vivia de forma tranquila, sendo possível dividir problemas, frustrações e compartilhar momentos de felicidade. Segundo o Vereador 2: "era uma comunidade acho que absolutamente pacífica, né... não lembro de eles enfrentarem nenhum tipo de problema com relação à violência [...]". A fala Jornalista 1 reitera: "[...] a característica é que as pessoas tinham uma aproximação maior entre elas, elas viviam talvez como uma família".

A palavra família é citada diversas vezes ao longo das entrevistas. O significado demonstrado nas falas é para além do que seria tratado no direito civil brasileiro, ou seja, envolvendo uma relação de pais, mães e filhos. Esse termo é usado para explicar que existiam relações estreitas entre vizinhos que não necessariamente tenham laços parentais, mas sim, uma relação que se aproxima das definições de comunidade apresentadas por Parker, Fournier e Reedy (2012).

Constatou-se que um dos motivos para essa aproximação entre os moradores envolvia a ampla biodiversidade da comunidade, devido à presença da lagoa de Jacarepaguá e de muitas árvores encontradas a priori na Vila Autódromo. De acordo com um dos moradores: "[...] a troca com os vizinhos era sensacional, os vizinhos davam uma fruta e você dava outra pra ele, batia no portão com aquele saco de manga, né, aí uma levava um saco de abacate [...]". 
Entretanto, a existência de mais de 25 anos de possibilidade de remoções foi percebida como um aspecto redutor dos níveis de tranquilidade e segurança, mas que, ao mesmo tempo, fez com a comunidade se organizasse. Segundo o Vereador 2, a própria história de luta dos moradores foi um fator decisivo, pois, talvez, se anteriormente tivesse havido um processo de remoção mais intensificado, tais moradores não dispusessem de tamanha força de articulação e confronto para lidar com tal situação. Pois, segundo ele, quando o poder público chega mais rápido, "de maneira mais esmagadora, fica mais difícil resistir" (Vereador 2).

De maneira geral, as falas dos entrevistados vão ao encontro do que foi argumentado por Oliver-Smith (1991), ou seja, que o histórico de tentativas, experiências vividas em relação à defesa de seus interesses com resultados positivos afetam a capacidade de resistência da comunidade. Assim, o processo de remoção de casas na Vila Autódromo se deu por motivações diferenciadas que oscilam, principalmente, entre a lógica neoliberal de crescimento econômico urbano e melhorias ambientais, duas das justificativas para remoções urbanas apontadas por Cernea (1993). O que se verificou no histórico processo de remoções da comunidade foram o interesse e a necessidade acerca da região para expansão comercial e para outros objetivos de cunho empresarial, percebendo-se, portanto, o empirismo teorizado por Cernea (1993). Isto é, com o crescimento econômico urbano da cidade do Rio de Janeiro, houve a intensificação da concorrência para áreas mais vazias da cidade, o que resultou em um esforço por parte de setores públicos e privados na implantação de investimentos comerciais naquela área, excluindo assim seus antigos moradores (devido baixo poder aquisitivo).

Inicialmente, foi concedido aos moradores o pagamento de aluguel social como alternativa habitacional até que a construção do conjunto habitacional Parque Carioca, financiado pelo Programa Minha Casa Minha Vida, fosse finalizada (MONTEIRO; MEDEIROS, 2016). Em 2011, foi lançado o edital de licitação para a concessão do terreno público e constituição da parceria público-privada, que apresentou como único licitante o consórcio composto pelos grupos Odebrecht, Andrade Gutierrez e Carvalho Hosken (MONTEIRO; MEDEIROS, 2016).

O Parque Carioca foi construído acerca de $2 \mathrm{~km}$ da antiga comunidade, para moradores da Vila Autódromo que optaram pelo reassentamento, algo raro em se tratando de casos de remoção no Rio de Janeiro (MONTEIRO; MEDEIROS, 2016). Ainda assim, e a partir de trechos das entrevistas, há relatos de demolições que se sucederam sem a retirada de escombros prévios (de casas desocupadas de moradores que iriam para o Parque Carioca), comprometendo assim as residências remanescentes dos moradores que se recusaram a sair da região. Isto é, mesmo respaldadas legalmente, houve remoções de maneira ilegítima.

Ainda sobre as formas como se deram as demolições, tem-se os depoimentos do Morador 1 e da Defensora Pública 2, ao relatarem prejuízos sofridos por uma criança de quatro anos e uma idosa de 80 anos. Isso vai de encontro com um dos critérios descrito no Guia produzido pela Relatoria Especial da ONU para a moradia adequada, já que, nesse caso, não houve a precaução adequada com duas pessoas pertencentes aos grupos considerados vulneráveis (ONU, 2010). Também se constatou a ausência de assistência adequada de transporte para a retirada dos pertences dos moradores que optaram pela saída da comunidade, como é exigido no Guia (ONU, 2010). Além disso, as imagens na página da comunidade no Facebook, somadas às falas dos entrevistados, demonstraram a presença constante de um constante trepidar dos tratores, além da falta d'água durante o processo de remoção na comunidade, fatos que afetavam a habitalidade. Ademais, os entrevistados afirmaram que não houve a necessidade de que algumas demolições acontecessem de fato.

De acordo com a Pesquisadora 1, dentre os decretos de desapropriação estava o da Associação de Moradores, terreno que está vazio até hoje. Isto é, onde estava localizada a Associação de Moradores, por exemplo, hoje, não existe nada que seja para fins de interesse público. Isso viola a noção de que as remoções só devam acontecer em casos estritamente necessários (ONU, 2010). Além disso, as imagens e falas apresentam o uso de violência física no dia 03 de junho de 2015.

A forma questionável como ocorreu o processo de remoção de casa da comunidade atraiu indivíduos de maneira isolada e organizações que se tornaram mais presentes na comunidade, como a Defensoria Pública, as universidades, a Igreja Católica, as mídias alternativas, e os partidos políticos. Assim, a partir da fala dos entrevistados e dos dados do Plano Popular, é possível inferir que muitas organizações trabalharam em conjunto na Vila Autódromo. Sobre isso, um dos moradores afirmou que: "[...] a gente costuma dizer que essa luta foi tecida por vários [...] foi como uma colcha de retalhos [...]" (Morador 1). Por isso, é complicado registrar todas essas organizações. Entretanto, no decorrer da pesquisa é perceptível a repetição e algumas organizações, talvez não por uma atuação específica, mas pelo tempo e constância durante o processo de resistência da comunidade.

Algumas organizações com presença constante nos discursos, como a Igreja, a Defensoria Pública e as universidades, se incluem nas características dispostas por Misockzy e Moraes (2011) enquanto organizações verticais a partir de características como: concentração de poder (poucos decidem e muitos executam); hierarquia; regras legitimadas que definem o funcionamento das organizações; e um sistema de regulação para garantir a obediência. Em contrapartida, a Associação de Moradores, apesar de ter características de uma organização vertical, como cargos e Estatuto, demonstrou ser um espaço de aprendizagem e de participação, com ações desenvolvidas em coletivo e a oposição às estratégias remocionistas respaldadas pelas políticas de empresariamento urbano.

Sabendo que os movimentos sociais também fizeram parte da luta da comunidade, o Movimento União Popular 
(MUP) foi um movimento que, de acordo com uma das entrevistadas, surgiu em 2004 e abarcava 32 comunidades. Segundo a Ex-Moradora 2, a intenção era " [...] construir uma rede de solidariedade entre aqueles que estavam ...nessa situação de ameaça". Já segundo a Ex-Moradora 1, a Associação começou a buscar apoio de outras comunidades ameaçadas de remoção, surgindo o MUP, que, a partir desse movimento, pensavam-se decisões para a realização efetiva dos direitos dos moradores dessas comunidades.

Assim, esse movimento demonstrou importância para a construção das ações de resistência realizadas na comunidade. Ou seja, devido ao fato de outras comunidades participarem do movimento, verificou-se que havia a troca de experiência (GOHM, 1990) a partir da socialização de informações e da construção de identidades, podendo ser citada a constituição dessas comunidades e de outras que vislumbrassem a possibilidade de remoção como AEIS.

Além do MUP, outra organização importante na comunidade foi a Associação de Moradores, pois, historicamente, contribuiu para a legalização da comunidade e para conquista de direitos, como os 85 termos de Concessão de Direito Real de Uso (MEDEIROS; MONTEIRO, 2016). Além disso, a Vila Autódromo foi declarada como Área de Especial Interesse Social (AEIS) do município do Rio de Janeiro, o que reafirma a destinação da área à habitação de interesse social (MEDEIROS; MONTEIRO, 2016). Os dados demonstraram que a Associação foi criada a partir da percepção que, por vivermos em uma sociedade permeada por organizações burocráticas, as regras e normas transparecem um aspecto formal para a luta, o que auxilia o reconhecimento da mesma. É interessante perceber esse nível de consciência que se transformou na busca pela legalização da Associação. Sendo assim, foi feita a regulamentação, dentro dos trâmites burocráticos, da Associação enquanto uma organização "normal" - ou seja, formal, hierárquica e delimitada - e que prezasse pela administração ou manutenção das coisas (BÖHM, 2006). Entretanto, os dados apontaram que a intenção dos moradores que buscaram a legalização era com o intuito de a Associação ser um espaço em que houvesse a participação direta, com decisões tomadas no coletivo.

A forte presença das Universidades na luta em torno da comunidade se deu a partir da construção do Plano Popular da Vila Autódromo. A construção desse Plano ocorreu pela articulação entre a Universidade Federal Fluminense, a Universidade Federal do Rio de Janeiro e a Associação de Moradores e Pescadores da Vila Autódromo. De acordo com o Vereador 2, o Plano Popular, além da importância de ter sido premiado internacionalmente, foi uma peça que desmontava todos os argumentos pela remoção. O Plano Popular, não só o Plano finalizado em si, mas, também, sua construção, é um exemplo que clarifica o que Rauber (2004) identifica como sendo a articulação entre o conhecimento técnico, científico e o popular.

A Defensoria Pública, especificamente o Núcleo de Terras e Habitação (NUTH), também, foi ressaltada pela maioria dos entrevistados como importante para as ações de resistência no âmbito da comunidade Vila Autódromo. De acordo com o Ex-Morador 1, a Defensoria teve um papel importante na luta da Vila Autódromo por estar presente em muitas reuniões realizadas na comunidade, além de ter atuado na defensoria e explicação dos direitos dos moradores.

As análises apontaram que a Igreja Católica também foi uma organização importante para as ações de resistência na comunidade. Entretanto, a Ex-moradora 1 e Ex-diretora social da Associação de Moradores ressaltou que a religião em si pode limitar as participações na luta, por, possivelmente, diminuir a autonomia na resistência. Ela afirmou que nunca quis se vincular a nenhum tipo de religião, pois o papel que escolheu desempenhar dentro da comunidade foi o de "parceira" para com outras comunidades, na busca por direitos, função que poderia vir a ser prejudicada a partir do rótulo da "religiosa", afastando aqueles que não fossem de sua mesma religião.

A mídia alternativa, aqui compreendida como um instrumento contra-hegemônico, ou seja, que se opõe a mídia favorável e ao status quo, prezando, então, pela transformação da sociedade a partir de um novo consenso em que o povo seja protagonista e gerador de conteúdo (KAPLÚN, 1985; KROHLING PERUZZO, 2008), foi apontada pela maioria dos entrevistados como importante nas ações de resistência no âmbito da Vila Autódromo. Compreende-se, portanto, que tal instrumento aumentou a visibilidade dessas ações, ou seja, o reconhecimento tanto do alvo como dos observadores sobre a resistência na comunidade (HOLLANDER e EINWOHNER, 2004), o que se denomina enquanto resistência aberta. Essa importância se ampliou com a participação dela em diversas ações, como na realização de documentários contando a história da comunidade e protagonizados pelos moradores.

Alguns partidos de oposição ao executivo municipal da cidade, mas vinculados ao legislativo, participaram das ações de resistência pela forma de mandatos, porém, ainda, com poucas atuações nas comunidades. De acordo com a Ex-Moradora 1: "a gente sempre teve uns quatro ou cinco políticos que vinham pro nosso meio fazer barulho e são os mesmos de hoje, são pessoas que vieram pra isso mesmo e que não se deixam corromper".

As características da Vila Autódromo, reconhecida internacionalmente enquanto comunidade politicamente atuante, a maneira como seu deu o processo de remoção na comunidade e as principais organizações envolvidas traçaram o caminho das ações de resistência. A priori, pode-se constatar que essas ações pertencem, majoritariamente ao tipo, denominado por Hollander e Einwohner (2004), de resistência aberta. Isso quer dizer que o comportamento dos atores é visível e reconhecido tanto pelo alvo como pelos observadores enquanto resistência (HOLLANDER; EINWOHNER, 2004). Tal constatação não significa que haja concordância quanto à percepção de legitimidade da resistência por todos os observadores, pois não há como mensurar todos eles (porém também não é o que este artigo se propõe a fazer).

Quanto ao alvo (para quem a ação é dirigida), os dados apontaram que, nos decretos e reuniões entre 
representantes da comunidade e o executivo municipal, havia o reconhecimento da resistência, sendo feitas negociações com valores altos, como ilustradas. De acordo com a Defensora Pública 2: "indenizações [...] pros padrões de favela [...] pros padrões que a gente conhecia, as indenizações já começaram altas, bem altas e foram crescendo [...] tinha indenização chegando a um milhão, um milhão". Segundo o Ex-Morador 1: "pagaram um milhão numa casa de pobre". A Moradora 1 ratificou esses dados: "[...] eles medem a minha casa por fora e botam um valor de 2 milhões e 400 também pra mim poder ir lá negociar, mas a minha família não foi [...]".

A maioria dos entrevistados questionou que a prefeitura sozinha não teria dinheiro para pagar indenizações nesses valores. Além disso, quando se reafirma a existência de uma política de empresariamento urbano na cidade, assume-se a existência de parcerias público-privadas, ampliando-se, consequentemente, o alvo da resistência para além do executivo. Não foi feito um comparativo entre as receitas do executivo e as indenizações pagas para se constatar a veracidade dessa informação sobre as indenizações. Entretanto, os entrevistados apontam essa questão. De acordo com o Ex-Morador 1: "[...] na verdade o que eles queriam era fazer uma limpeza ali por conta do empreendimento que vai acontecer ali dentro [...] todas as empresas que tão enroladas aí na propina, deu dinheiro pra tirar a Vila Autódromo". Segundo a Defensora Pública : "[...] depois a gente ficou sabendo que esse convencimento tinha um preço, uma certa vantagem que a prefeitura dava junto [...] é claro com as construtoras porque a prefeitura sozinha não ia ter investimento para fazer isso [...]'. Já a Ex-Moradora 2 destacou que houve o entendimento, por parte dos moradores, que eles eram indesejáveis e que a política imobiliária da Barra da Tijuca era declaradamente para empresários imobiliários. Quanto a isso, um empresário imobiliário brasileiro, proprietário de 6 milhões de metros quadrados na região da Barra da Tijuca, afirmou que essa região passaria a ser um local para pessoas com alto poder aquisitivo e sem a presença de comunidades pobres (WATTS, 2015). Dessa forma, constata-se que o alvo de resistência no âmbito da comunidade não era apenas o poder público e nem somente as empresas envolvidas nas parcerias público-privadas, mas sim, a política empresariamente urbana.

Outra categoria colocada por Hollander e Einwohner (2004), para se pensar a resistência, é a intenção dos atores com as ações de resistência. Quanto a isso, apesar de ter se constatado que, majoritariamente, o que se viu no âmbito da Vila Autódromo foi a resistência do tipo aberta, a pretensão com essa denominação não se tratou por inserir as ações em um paradigma fixo. Pois, se pensarmos de maneira macro, os atos que aconteceram na Vila Autódromo se enquadram no tipo aberta, mas, se pensarmos em ações de forma isolada, é possível percebermos outras intenções, ou nem mesmo ser possível perceber qual foi a real intenção do ator com aquela ação, pois questões subjetivas não foram analisadas. Neste sentido, os dados apresentaram que, em alguns momentos, a intenção dos atores foi colocada em xeque, além da possibilidade em existir dúvida por parte do autor se aquela ação foi ou não de fato uma ação de resistência. Mas, majoritariamente, constatou-se que as ações desenvolveram-se com a intenção de combater a política de empresariamento urbano envolvendo a comunidade, com o foco central para as remoções.

Contatou-se, também, que existiram na Vila Autódromo ações diretas sem o uso de violência física, exceto no episódio do dia 03 de junho de 2015 em que, de acordo com os dados, houve a iniciativa de uma ação violenta que partiu da Guarda Municipal do Rio de Janeiro, culminando em integrantes da guarda e da comunidade feridos ao final do episódio. Percebeu-se também a existência de ações com o envolvimento de canais, instâncias e recursos estatais - características da luta institucional (SOUZA, 2012). Dessa forma, a partir da sistematização no formato de tabela de todas as imagens postadas na página do Facebook da Vila Autódromo, constatou-se que a maioria das ações foram ações diretas - como ocupações, vigílias, atos de protesto e inserção de faixas. Mas claro que essa constatação não retira a importância das lutas institucionais. Até porque, os espaços participativos advindos da Constituição Federal de 1988, como as audiências públicas e as conferências da cidade, possibilitaram encontros com outras comunidades, políticos e etc.

Com a pandemia devido ao coronavírus e a impossibilidade de visitação ao Museu das Remoções, houve a mobilização de moradores, pesquisadores e apoiadores para a elaboração do percurso virtual pelo Museu e da comemoração de seus cinco anos de existência. O Museu é apresentado como "ferramenta de luta" do direito à cidade e à moradia, com conceitos advindos do meio acadêmico, ressaltando a importância da colaboração dos pesquisadores para a construção das ações. Também foi realizado um ciclo de lives sobre o museu no mês de agosto de 2020, tendo presidente do Horto - comunidade no Rio de Janeiro que luta há mais de três décadas para manter suas moradias - como uma das falas. Outra live aconteceu com o criador e realizador do projeto Ralé dos Favelados e também morador do Morro da Providência, primeira favela do Rio de Janeiro. Houve também encontros envolvendo experiências internacionais de direito à moradia, como a ocorrida em Granada, na Espanha; assim como o compartilhamento de imagens contrárias ao despejo no Catujal, Loures, Portugal.

Compreende-se, então, que essas ações reforçam a troca de experiências como um fator para a construção de experiências organizacionais de resistência, possibilitando a socialização de informações, o construir de identidades, o conhecer dos resultados obtidos por outros grupos e o reavivar de experiências passadas, conforme mencionado por Gohn (1991).

Conclui-se, portanto, que a construção dessas ações pautou-se no critério de solidariedade de Lightfoot (2013) e Parker et al. (2014), com ações construídas por meio da cooperação, prevalecendo a noção de que os indivíduos são seres sociais e dependentes uns dos outros. Se isolados, tornam-se vulneráveis, já coletivamente, tornam-se 
capazes de transformar a realidade. Compreende-se, então, que a coletividade foi um fator essencial na construção das ações e que as falas demonstram não haver atitudes negativas explícitas às sugestões de novas ações de resistência. Isto é, verificaram-se as existências de receptividade e abertura ao diálogo devido à conscientização de que ambos são relevantes para a construção de ações de resistência.

\section{CONCLUSÃO}

A partir das análises, constatou-se que alguns fatores são fundamentais para a construção de experiências organizacionais de resistência ao fenômeno de empresariamento urbano. São elas: histórico de lutas, aprendizagem e tomada de decisão na esfera coletiva, articulação com organizações aliadas, troca de experiências, presença de solidariedade e responsabilidade com o futuro a partir do respeito ao meio ambiente.

No caso da Vila Autódromo, o histórico de tentativas em relação à defesa de seus interesses obteve resultados positivos, já que a comunidade conquistou o título de Área de Especial Interesse Social (AEIS) e alguns moradores adquiriram a Concessão de Direito Real de Uso para moradia. Outro fator foi a existência de uma Associação de Moradores que prezava pela participação de todos, tornando-se um espaço de aprendizagem em que as discussões se davam, majoritariamente, na esfera coletiva, sem tomadas de decisões a partir de um único líder.

A participação de moradores no Movimento União Popular (MUP) também foi fundamental, pois promoveu a troca de experiência com outras comunidades e demonstrou ter sido importante para a construção da conscientização política, bem como, para a relação positiva entre os moradores que tornaram a Vila Autódromo uma comunidade, aqui entendida a partir da perspectiva de Parker, Fournier e Reedy (2012).

A situação de perigo, inicialmente, ampliou os vínculos de parte dos moradores - conforme descrito teoricamente por Hoffe (2003) -, além da solidariedade que acabou por envolver a noção de pertencimento a uma mesma comunidade (PARKER, FOURNIER, REEDY, 2012). A solidariedade também se refletiu na maneira receptiva como os moradores recebiam quem vinha apoiar as ações de resistência em torno da comunidade.

Também, verificou-se a responsabilidade com o futuro (LIGHTFOOD, 2013; PARKER et al., 2014), ou seja, o relacionamento dos moradores com o meio ambiente, e particularmente com a terra, que, conforme apontado por Oliver-Smith (1991) são laços importantes para resistir às remoções.

Alguns fatores apresentaram-se como responsáveis por atrair intensamente a presença da Defensoria Pública, das universidades, da Igreja Católica, das mídias alternativas e dos partidos políticos, como: a ausência de indícios evidentes de milícia ou de tráfico de drogas na comunidade e a forma questionável como ocorreu o processo de remoção das casas da comunidade. Assim, de maneira ampla, houve uma forte articulação entre essas organizações devido à oposição, à política de empresariamento urbano na cidade, e, de maneira mais específica, às remoções na comunidade. De tal modo, as ações desenvolvidas na comunidade foram consideradas a materialização da resistência, construídas coletivamente, e sendo muitas das vezes impossível de os entrevistados citarem quem sugeriu determinada ação.

É importante enfatizar que, ainda que o processo das remoções na comunidade tenha ocorrido de forma mais específica no contexto dos grandes eventos no município do Rio de Janeiro, os efeitos da luta por parte dos moradores perduram até os dias atuais, o que confere maior relevância aos resultados apresentados no presente trabalho. De fato, é bastante visível que, ainda nos dias de hoje, um número significativo de representantes de organizações políticas, culturais, acadêmicas e de movimentos sociais, provenientes do contexto nacional e internacional, venha a se interessar pelas experiências dos diferentes grupos que ali estiveram e que ainda estão presentes, o que faz com que diversos atores que vivenciaram tal fenômeno sigam ativamente em termos de atuação e compartilhamento de experiências.

Por fim, defende-se não haver fórmula pronta para a construção de experiências organizacionais de resistência ao fenômeno de empresariamento urbano, pois cada investigação poderá enxergar novos fatores e peculiaridades do espaço investigado. No entanto, apesar de toda explanação apresentada anteriormente, tem-se a ciência de não ter sido possível, para esse artigo, explorar todos os aspectos envolvendo o fenômeno da resistência, mas que se espera despertar a atenção para a existência de mundos organizacionais plurais que possam ser analisados de forma mais atenta e aprofundada pelos estudos no âmbito da Administração.

\section{REFERÊNCIAS}

ASSOCIAÇÃO DE MORADORES E PESCADORES DA VILAAUTÓDROMO. Estatuto da associação de moradores e pescadores da Vila Autódromo. Rio de Janeiro: AMPVA, 2008.

ASSOCIAÇÃO DE MORADORES E PESCADORES DA VILA AUTÓDROMO. Plano popular da Vila Autódromo. Rio de Janeiro: AMPVA, 2016.

ATTON, C. Alternative media. London: Sage, 2002. 
BETIM, F. Remoções na Vila Autódromo expõem o lado B das Olimpíadas do Rio. El País, Rio de Janeiro, 5 ago. 2015. Disponível em: Link. Acesso em: 20 nov. 2016.

BÖHM, S. Repositioning organization theory: impossibilities and strategies. New York: Palgrave Macmillan, 2006.

CERNEA, M. M. The urban environment and population relocation. Washington: World Bank, 1993. (World Bank Discussion Papers, 152)

CERNEA, M. M. Reassentamento populacional e desenvolvimento. Finanças \& Desenvolvimento, [S. I.], v. 18, n. 1. p. $46-49,1994$.

COSTA, P. de A. et al. Provocações epistemológicas, teóricas e metodológicas a partir de experiências empíricas de organizações alternativas e contra hegemônicas. Farol Revista de Estudos Organizacionais e Sociedade. Belo Horizonte, v. 5, n. 13, p. 477-495, ago. 2018.

GOHN, M. Movimentos sociais e luta pela moradia. São Paulo: Loyola, 1991.

HARVEY, D. Do gerenciamento ao empresariamento: a transformação da administração urbana no capitalismo tardio. Espaço \& Debates. Revista de Estudos Regionais e Urbanos, São Paulo, n. 39, p. 48-64, 1996.

HOLLANDER, J. A.; EINWOHNER, R. L. Conceptualizing resistance. Sociological Forum, [S. I.], v. 19, p. 533-554, 2004.

HÖFFE, O. O que é justiça. Porto Alegre: EDIPUCRS, 2003.

KAPLÚN, M. El comunicador popular. Quito: CIESPAL, 1985.

KROHLING PERUZZO, C. Conceitos de comunicação popular, alternativa e comunitária revisitados. Reelaborações no setor. Palabra Clave, Colômbia, v. 11, n. 2, p. 1-14, 2008.

LACLAU, E.; MOUFFE, C. Hegemonía y estrategia socialista: hacia una radicalización de la democracia. Madrid: Siglo XXI, 1987.

LIGHTFOOT, G. Imagining alternatives. In: PARKER, M.; CHENEY,. G.; FOURNIER.V.; LAND, C. The routledge companion to alternative organization. London: Routledge, 2013. p. 31-41.

MASCARENHAS, G. Cidade mercadoria, cidade-vitrine, cidade turística: a espetacularização do urbano nos megaeventos esportivos. Caderno Virtual de Turismo. Rio de Janeiro, v. 14, p. 52-65, nov. 2014. Edição especial Hospitalidade e políticas públicas em turismo.

MISOCZKY, M. C.; FLORES, R. K.; BÖHM, S. A práxis da resistência e a hegemonia da organização. Organizações \& Sociedade, Salvador, v. 15, n. 45, p. 181-193, abr./jun. 2008.

MISOCZKY, M. C. Das práticas não-gerencias de organizar à organização para a praxis da libertação. In: MISOCZKY, M. C.; FLORES, R. K.; MORAES, J. (org.). Organização e praxis Libertadora. Porto Alegre: Dacasa, 2010. p. 13-56.

MONTEIRO, P. G.; MEDEIROS, M. G. P. O sistema de justiça e a luta pela moradia no Rio de Janeiro: o percurso jurídico da resistência da Vila Autódromo contra a remoção. Revista Brasileira de Direito Urbanístico, Belo Horizonte, n. 7, a. 4, p. jul./dez. 2018.

OLIVER-SMITH, A. Involuntary resettlement, resistance and political empowerment. Journal of Refugee Studies, [S. I.], v. 4, n. 2, p. 132-149,1991.

OLIVER-SMITH, A. Fighting for a place: the policy implications of resistance to development-induced resettlement. In: MCDOWELL, C. (ed.) Understanding impoverishment: the consequences of development-induced displacement. Oxford: Berghahn Books, 1996. p. 77-97.

ORGANIZAÇÃO DAS NAÇÕES UNIDAS. Como atuar em projetos que envolvem despejos e remoções?. Guia. Relatoria Especial da ONU para a moradia adequada. São Paulo: ONU, 2010. Disponível em: Link. Acesso em: 5 set. 2017. 
PARKER, M. Against management: organization in the age of managerialism. Cambridge: Polity, 2002.

PARKER, M.; FOURNIER, V.; REEDY, P. Dicionário de alternativas. São Paulo: Octavo, 2012.

PARKER, M; CHENEY, G; FOURNIER, V; LAND, C. The question of organization: a manifesto for alternatives. Ephemera, [S. I.], v. 14, n. 4, p. 623-628, 2014.

RAMOS, A. G. A nova ciência das organizações. Rio de Janeiro: Fundação Getúlio Vargas, 1989.

RAUBER, I. La transformación social en el siglo XXI: camino de reformas o de revolución. [S. I.]: Pasado y Presente XXI, 2004. ROLNIK, R. Jogos Olímpicos e direito à moradia adequada. Cienc. Cult., São Paulo, v. 68, n. 2,p. 31-36, jun. 2016. Disponível em: Link. Acesso em: 30 maio 2021.

SPICER, A.; BÖHM, S. Moving management: theorizing struggles against the hegemony of management. Organization Studies, [S. I.], v. 28, n. 11, p. 1667-1698, 2007.

SOLÉ, A. L'entreprise: une invention Latine? In: COLÓQUIO INTERNACIONAL SOBRE PODER LOCAI, 9., 2003, Salvador. Anais [...]. Salvador: UFBA, 2003. p. 1-20.

SOUZA, M. Ação direta e luta institucional: complementaridade ou antítese? PassaPalavra. [S. l.: s. n.], 2012. Disponível em: Link. Acesso em: 30 nov. 2017

TAFAKGI, M. Copa e Olimpíadas pra quem? Uma etnografia sobre os impactos sociais e as mobilizações coletivas no processo de preparação do Rio de Janeiro como sede de megaeventos esportivos. Revista Ensaios, Niterói, v. 7, p. 1-16, 2016.

VINUTO, J. A amostragem em bola de neve na pesquisa qualitativa: um debate em aberto. Temáticas, Campinas, n. 44, p. 201-218, 2015.

WATTS, J. O empresário carioca na esperança de um legado olímpico próprio de bilhões. The Guardian in Portugues, Rio de janeiro, 12 ago. 2015. Disponível em: Link. Acesso em: 20 dez. 2017.

\section{Contato:}

Gabriela Izabel de Alvarenga

E-mail: gabriela.i.alvarenga@gmail.com

Leonardo Vasconcelos Cavalier Darbilly

E-mail: leonardo.darbilly1@gmail.com 